\title{
Correction: Development and evaluation of a high throughput inhalation model for organic chemicals
}

Matthew W. Linakis - Risa R. Sayre - Robert G. Pearce - Mark A. Sfeir - Nisha S. Sipes - Heather A. Pangburn • Jeffery M. Gearhart · John F. Wambaugh

Published online: 9 July 2020

(c) US Govt 2020

Correction to: Journal of Exposure Science \& Environmental Epidemiology

https://doi.org/10.1038/s41370-020-0238-y

In the original Article, Dr. John Wambaugh's was erroneously affiliated with the National Institute of Environmental
Health Sciences, Research Triangle Park. We have amended this, and Dr. Wambaugh's correct affiliation (with the National Center for Computational Toxicology, United States Environmental Protection Agency) is now reflected in the HTML, PDF and XML versions of this Article. 